\title{
RETRIEVAL OF ATMOSPHERIC PARTICULATE MATTER USING SATELLITE DATA OVER CENTRAL AND EASTERN CHINA
}

\author{
G. L. Chen ${ }^{1,3}$, J. Guang ${ }^{1, *}$, Y. Li $^{1,2}$, Y. H. Che ${ }^{1,2}$, S. Q. Gong ${ }^{3}$ \\ ${ }^{1}$ Key Laboratory of Digital Earth Science, Institute of Remote Sensing and Digital Earth, Chinese Academy of Sciences, Beijing \\ 100094, China - guangjie@radi.ac.cn \\ ${ }^{2}$ University of Chinese Academy of Sciences, Beijing 100049, China - (happyappleliying, 15011546747)@163.com \\ ${ }^{3}$ School of Geography and Remote Sensing, Nanjing University of Information Science \& Technology, Nanjing 210044, China - \\ (guilichen1992, shaoqigong)@163.com
}

KEY WORDS: Retrieval, Atmospheric Particulate Matter, Satellite, Central and Eastern China

\begin{abstract}
:
Fine particulate matter $\left(\mathrm{PM}_{2.5}\right)$ is a particle cluster with diameters less than or equal to $2.5 \mu \mathrm{m}$. Over the past few decades, regional air pollution composed of $\mathrm{PM}_{2.5}$ has frequently occurred over Central and Eastern China. In order to estimate the concentration, distribution and other properties of $\mathrm{PM}_{2.5}$, the general retrieval models built by establishing the relationship between aerosol optical depth (AOD) and $\mathrm{PM}_{2.5}$ has been widely used in many studies, including experimental models via statistics analysis and physical models with certain physical mechanism. The statistical experimental models can't be extended to other areas or historical period due to its dependence on the ground-based observations and necessary auxiliary data, which limits its further application. In this paper, a physically based model is applied to estimate the concentration of $\mathrm{PM}_{2.5}$ over Central and Eastern China from 2007 to 2016. The ground-based $\mathrm{PM}_{2.5}$ measurements were used to be as reference data to validate our retrieval results. Then annual variation and distribution of $\mathrm{PM}_{2.5}$ concentration in the Central and Eastern China was analysed. Results shows that the annual average PM 2.5 show a trend of gradually increasing and then decreasing during 2007-2016, with the highest value in 2011.
\end{abstract}

\section{INTRODUCTION}

Atmospheric particulate matter (PM) is a general term for solid and liquid particles suspended in the atmosphere. $\mathrm{PM}_{2.5}$ is the integrated mass of dry aerosol particles with an aerodynamic diameter of less than or equal to $2.5 \mu \mathrm{m}$. With rapid economic development and urbanization, regional air pollution composed of PM has frequently occurred in Central and Eastern China. As the primary pollutant in urban air, PM is important for global climate change (Steiner et al., 2013), local air quality (Guo et al., 2014) and human health (Künzli and Tager, 2006). At present, information on PM can obtained from ground-based observations and from the use of remote sensing methods. Ground-based observation is the most conventional and reliable method for monitoring PM concentration, but studies for the spatial characteristics of PM requires sufficiently dense and expensive ground-based observation networks. Furthermore, the spatial distribution of the ground-based data and the lack of historical data limit the further application of the existing ground-based observation datasets. In comparison, satellite remote sensing has the advantage of covering large areas on a wide spatial scale and long-term observation (Liu, 2013). The long-term continuous observations make it possible to get historical PM data. However, the information is limited to the overpass time of the satellite, and the availability of visible light, which limits the observations to a several hours around local noon. Also, satellite observations of aerosols require clear sky, i.e. they can only be made in the absence of clouds. Furthermore, satellite-based retrieval for near surface concentration of $\mathrm{PM}_{2.5}$ is still in the initial stage of development and no reliable satellite derived $\mathrm{PM}_{2.5}$ product is available except for the 1998-2012 annual average dataset by the
Socioeconomic Data and Application Center (SEDAC) (http://sedac.ciesin.columbia.edu/).

The estimation of the concentration, distribution and other properties of $\mathrm{PM}_{2.5}$ from satellite data rely on developing relationship between satellite-based aerosol optical depth (AOD) data and ground-based $\mathrm{PM}_{2.5}$ observations. Many attempts to develop such relations have been published, including experimental models via statistics analysis and physically based models. For those studies on statistical models, mainly including linear regression models (Liu, 2005), multiple linear regression models (Zhang et al., 2016), non-linear model (Liu et al., 2009), artificial neural network models (Wang et al., 2013) and the mixed effect models (Xie et al., 2015). However, the statistical models can't be extended to other areas or historical period due to its dependence on ground-based observations and necessary auxiliary data, which limits its further application. While the physically based model is mainly based on the mature chemical transport model (van Donkelaar et al., 2014), it does not need ground-based $\mathrm{PM}_{2.5}$ observations as a priori knowledge to build a model. For example, van Donkelaar et al. (2014) retrieved $\mathrm{PM}_{2.5}$ concentration on the global scale. However, as AOD reflects the aerosol optical properties of the total column while the PM concentration is usually measured at surface level, the correlation between them is severely influenced by the vertical distribution of aerosols and the relative humidity $(\mathrm{RH})$ that impacts aerosol extinction coefficient. Koelemeijer et al. (2006) found that the correlation between PM and AOD can be improved when the AOD is corrected by the boundary layer height and relative humidity over Europe. Space-borne $\mathrm{PM}_{2.5}$ retrieval has made great advances in recent years, but many issues remain, including the determination of influential factors on the correlation between

\footnotetext{
* Corresponding author
} 
satellite AOD and ground-based $\mathrm{PM}_{2.5}$. In this paper, we describe a physically based approach to retrieve $\mathrm{PM}_{2.5}$ with satellite AOD data, which is independent of ground-based $\mathrm{PM}_{2.5}$ measurements. Firstly, the study area and data used in this paper are shown, then the $\mathrm{PM}_{2.5}$ retrieval model is introduced. Thirdly, $\mathrm{PM}_{2.5}$ concentration in the Central and Eastern China is retrieved and validated by ground-based data. After that annual variation and distribution of $\mathrm{PM}_{2.5}$ concentration in the Central and Eastern China was analysed. A short summary is presented at last.

\section{STUDY AREA AND DATA}

\subsection{Study Area}

In this paper, Central and Eastern China $\left(110^{\circ} \mathrm{E} \sim 125^{\circ} \mathrm{E}\right.$, $20^{\circ} \mathrm{N} \sim 43^{\circ} \mathrm{N}$ ) is taken as the study area, including the eastern regions of China (Beijing, Tianjin, Hebei, Shanghai, Jiangsu, Zhejiang, Fujian, Shandong, Guangdong, and Hainan provinces), and the central regions of China (Shanxi, Anhui, Jiangxi, Henan, Hubei, and Hunan provinces. This area has the main population of China. With the rapid development of economy and the acceleration of urbanization, a large number of pollutants are discharged into the air, making the local atmosphere worse, and frequent atmospheric pollution events such as haze occurs in this region.

\subsection{Data}

2.2.1 Satellite Data: The moderate-resolution imaging spectroradiometer (MODIS) provides the best monitoring aerosol properties from the space so far (Levy et al., 2013). MODIS instruments onboard EOS-Terra with the overpasses at 10:30 am (LST), and the other is onboard EOS-Aqua with the overpasses at 1:30 pm. The MODIS aerosol parameters are provided at a normal spatial resolution of $10 \mathrm{~km} \times 10 \mathrm{~km}$ in Level (L) 2 data (MOD04 for Terra and MYD04 for Aqua). MODIS aerosol retrieval over land is first realized by the Dark Target (DT) algorithm over vegetated regions, and then Deep Blue (DB) aerosol retrieval is developed to cover bright land surface in C5. An extensive effort of validation using Aerosol Robotic Network (AERONET) AOD measurement indicates that the MODIS products have an accuracy of $\pm 0.05 \pm 0.15 \tau$ over land globally (Levy et al., 2013). Ground validations show that DT retrievals over Northern China obviously overestimated the aerosol loading but tended to miss the common regional haze pollution in China, and DB retrievals tended to underestimate AOD in North-western and Southern China. Although still with overestimated trend, DT performed a little better over Southern China, where dense vegetation is prevalent (Tao et al., 2015). There is a new data set combing DT and DB in C6. The global MODIS AOD products have been provided on NASA's website (https://ladsweb.modaps.eosdis.nasa.gov/). The C6 MODIS aerosol products (MOD04\&MYD04) are used in this paper.
2.2.2 Meteorological parameters: The European Centre for Medium-Range Weather Forecasts (ECMWF) was established in 1975. Since then the Centre's archive of analyses and forecasts has become an important source of data for research used extensively by the Centre's staff and by scientists from all around the world (Dee et al., 2011). Now we can download the reanalysis data such as relative humidity $(\mathrm{RH})$ contained in pressure levels and boundary layer height (BLH) from 1979 to 2017 at different sizes grids and temporal resolutions (von Engeln and Teixeira, 2013). For the accuracy of the BLH, Guo et al. (2016) has conducted a comprehensive investigation of the BLH in China from January 2011 to July 2015 by using the fine-resolution sounding observations and reanalysis data. The comparison of seasonally averaged BLHs derived from observations and reanalysis, on average, shows good agreement The meteorological parameters (RH and $\mathrm{BLH}$ ) for the Central and Eastern China are collected from the ECMWF website (http://www.ecmwf.int/en/research). Here, the RH grid of $0.125^{\circ}$ by $0.125^{\circ}$ latitude/longitude with a 6-hour temporal resolution is used, and the BLH grid of $0.125^{\circ}$ by $0.125^{\circ}$ latitude/longitude with a 12 -hour temporal resolution is used.

\subsubsection{Ground-based $\mathbf{P M}_{2.5}$ observational data: The China} National Environmental Monitoring Center (http://www.cnemc.cn/) is a public institution directly under the Ministry of Environmental Protection and provides hourly data of AQI, $\mathrm{PM}_{2.5}, \mathrm{PM}_{10}, \mathrm{SO}_{2}, \mathrm{NO}_{2}, \mathrm{O}_{3}$ and $\mathrm{CO}$ at 1497 sites across the country. $\mathrm{PM}_{2.5}$ routine monitoring began in 2013.

\section{METHOD}

Much research on $\mathrm{PM}_{2.5}$ estimation from remote sensing data is based on statistical models. In this study, we develop an approach that uses the physically based $\mathrm{PM}_{2.5}$ retrieval model proposed by Koelemeijer et al. (2006) and evaluate by Chen et al. (2018) using AERONET data.

\subsection{Physically based $\mathbf{P M}_{2.5}$ Estimation Model}

In the Mie theory, aerosol extinction coefficients $(\mathrm{Ka})$ is defined as a function of the particle size distribution and the extinction characteristics of particles in the ambient air, which is expressed as (Liou, 2004):

$$
K_{a}=\pi \int_{0}^{X / 2} Q_{e x t}(m, r, \lambda) n(r) r^{2} d r
$$

where $Q_{\text {ext }}(m, r, \lambda)$ is the aerosol extinction efficiency, $m$ stands for the complex refraction index that depends on the chemical composition of the aerosol particles, and $n(r)$ represents the particle size distribution. $X / 2$ denotes the upper limit of the particle's radius in the integral. Considering the aerosol size distribution, the mass concentration of PM is expressed as:

$$
P M_{X}=\frac{4}{3} \pi \rho \int_{0}^{X / 2} r^{3} n(r) d r
$$

where $\rho$ is the average mass density of the particles (with a unit of $\mathrm{g} / \mathrm{cm}^{3}$ ). Here, $\rho$ is valued at $1.5 \mathrm{~g} / \mathrm{cm}^{3}$ (Zhang and $\mathrm{Li}, 2015$ ). According to Hansen and Travis (1974), the size-distribution integrated extinction efficiency $<$ Qext $>$ is defined as 


$$
<Q_{e x t}>=\frac{\int_{0}^{X / 2} Q_{e x t}\left(m_{s} r_{s} \lambda\right) n(r) r^{2} d r}{\int_{0}^{X / 2} n(r) r^{2} d r}
$$

and the effective radius $r_{\text {eff }}$ is defined as

$$
r_{\text {eff }}=\frac{\int_{0}^{X / 2} r^{3} n(r) d r}{\int_{0}^{X / 2} r^{2} n(r) d r}
$$

Combining Eqs. (1) to (4)

$$
K a=\frac{3<Q_{e x t}>}{4 r_{e f f}^{*} \rho} P M_{X}
$$

$\mathrm{Ka}$ obtains from AOD after vertical and humidity correction. $<$ Qext $>$ represents the size-distribution integrated extinction efficiency. PMx represents the atmospheric particulate matter concentration ( $\mathrm{PM}_{10}$ or $\mathrm{PM}_{2.5}$ respectively) with a unit of $\mu \mathrm{g} / \mathrm{m}^{3}$; $r_{\text {eff }}$ represents the effective radius describing the aerosol size distribution (with a unit of $\mu \mathrm{m}$ ). Here, $X$ is valued at 2.5. Combined with the definition of the $\left\langle\right.$ Qext $>$ and $R_{\text {eff }}$ value by the aerosol type in the MODIS dark image element algorithm (Levy et al., 2009), as shown in Table 1, the $\mathrm{PM}_{2.5}$ is computed using the physical method in this paper.

\begin{tabular}{|l|c|c|}
\hline Aerosol Model & Qext & $R_{\text {eff }}(\mu \mathrm{m})$ \\
\hline Continental & 0.6210 & 0.292625 \\
Moderately Absorbing & 1.0180 & 0.261287 \\
Non-absorbing & 0.9770 & 0.256210 \\
Absorbing/Smoke & 1.1720 & 0.207507 \\
Spheroid/Dust & 1.3390 & 0.679582 \\
\hline
\end{tabular}

Table 1. Extinction properties of the aerosol models

\subsection{Vertical Correction}

AOD represents the total extinction coefficient of aerosol integrated over the atmospheric column. To connect AOD with ground-level $\mathrm{PM}_{2.5}$ concentration, the relationship between AOD and the aerosol extinction coefficient near the surface needs to be evaluated. Accordingly, in order to get the extinction coefficient of the near ground aerosol, the vertical correction of AERONET AOD is carried out so as to eliminate influence of non-uniform distribution of particle in vertical direction. Under the assumption of plane parallel atmosphere, AOD $\left(\tau_{\mathrm{a}(\lambda)}\right)$ is defined as the integral of aerosol extinction coefficients $(\mathrm{Ka})$ over the whole atmospheric column (Liou, 2004), that is

$$
\tau_{a(\lambda)}=\int_{0}^{\infty} K_{a}\left(\lambda_{s} z\right) d z
$$

where $K a(\lambda, z)$ represents the extinction coefficient $(K a)$ at wavelength $\lambda$ and height $z$. The vertical distribution of $K a(\lambda, z)$ is described by an exponential function as the following form:

$$
K_{a}(\lambda, z) \approx K_{a, a(\lambda)} \exp \left(-z / H_{A}\right)
$$

where $H_{A}$ is the scale height of aerosol (with a unit of $\mathrm{m}$ ) and $K a, o(\lambda)$ is the aerosol extinction coefficient at the surface $(z=0)$.
The aerosol scale height is defined as the height at which the aerosol extinction coefficient is reduced to $1 / \mathrm{e}$ of the ground value. $H_{A}$, which is regarded as the equivalent depth of the optically active aerosol layer of the atmosphere and can be approximated by the boundary layer height (BLH) (Koelemeijer et al., 2006). Substituting Eq. (7) into Eq. (6), we have

$$
\tau_{a(\lambda)} \approx K_{a, a(A)} \int_{0}^{\infty} \exp \left(-\frac{z}{H_{A}}\right) \mathrm{dz}=K_{a, Q(\lambda)} \cdot H_{A}
$$

Eq.(8) can be used to estimate $K_{a, o(\lambda)}$ (surface-level aerosol extinction coefficient at wavelength $\lambda$ ) from the measured AOD and the BLH available from ECMWF re-analysis data (Li et al., 2005).

\subsection{Humidity Correction}

As the air sample is heated to $50{ }^{\circ} \mathrm{C}$, the PM concentrations measured by TEOM represent the "dry mass" of the particles in the air sample. Owing to the hygroscopic growth of aerosol, the extinction characteristics will change be significantly from those in ambient conditions (Tao et al., 2015). Hence, for a proper comparison of AOD with $\mathrm{PM}_{2.5}$, the effects of RH need to be accounted for. In this study, we correct the $K_{a, o(\lambda)}$ to get the extinction coefficient of dry aerosol by a hygroscopic growing factor $f_{(\mathrm{RH})}$, which, on the basis of previous studies (Im et al., 2001), can be defined as

$$
f_{(R H)}=\left(\begin{array}{ll}
1 & R H / 100
\end{array}\right)^{-g}
$$

where $g$ is an empirical fit coefficient, and here is valued at 0.38 , considering that the air mass in Central and Eastern China is classified as polluted continental air mass. The value of $g$ was calculated to be $0.38 \pm 0.03$ for polluted continental air masses, $0.37 \pm 0.05$ for continental air masses, and $0.38 \pm 0.05$ for marine air masses (Im et al., 2001). RH stands for relative humidity. Hence the "dry" $K_{a, o(\lambda)}$ is obtained through the application of the humidity correction.

$$
K_{a, D r y(A)}=K_{a, \Delta(A)} / f_{(R H)}
$$

In summary, by combining Eqs. (8) and (10), the "dry" aerosol extinction coefficient at surface level can be obtained from the AOD through the vertical correction and humidity correction:

$$
K_{a, D r y y}(\lambda)=\tau_{a(\lambda)} /\left[H_{A} \cdot f_{(R H)}\right]
$$

BLH and RH in the Central and Eastern China obtained from the ECMWF are used for vertical and humidity correction. During this process, it is important to make all parameters match in time and space, and the criteria used in this study is to use the closest in time and distance.

\section{RESULTS AND DISCUSSION}

\subsection{Validation}

In order to evaluate the accuracy of $\mathrm{PM}_{2.5}$ retrieval results, ground-based $\mathrm{PM}_{2.5}$ observatory data from 2014 to 2016 was used for validation. In this paper, the results of satellite retrieved $\mathrm{PM}_{2.5}$ in the cities of Beijing, Shijiazhuang, Tangshan, Nanjing and Changsha are validated as shown in Figure 1. Results show that correlation coefficient $(R)$ of retrieved $\mathrm{PM}_{2.5}$ versus ground-based $\mathrm{PM}_{2.5}$ is greater than 0.54 in Beijing, 
Tangshan, and Nanjing city, while $R$ in Shijiazhuang and Changsha city is slightly lower $(R=0.48)$. The root mean square error (RMSE) is better in Southern China $\left(36.48 \mu \mathrm{g} / \mathrm{m}^{3}\right.$ and $33.13 \mu \mathrm{g} / \mathrm{m}^{3}$ in Nanjing and Changsha, respectively) than in Northern China (over $53.39 \mu \mathrm{g} / \mathrm{m}^{3}$ in Beijing, Shijiazhuang, and Tangshan). The colours of dots represent density distribution of matches. Most of the points are on the 1:1 identity line, only retrieval results in Nanjing has a slightly overestimated. This result is comparable with other work based on physically based methods (Koelemeijer et al., 2006; Zhang and Li, 2015; Yang et al., 2017). Generally speaking, the $\mathrm{PM}_{2.5}$ concentration based on satellite product and this physical method has certain accuracy, and it has some applicability to the study of $\mathrm{PM}_{2.5}$ concentration in Central and Eastern China.
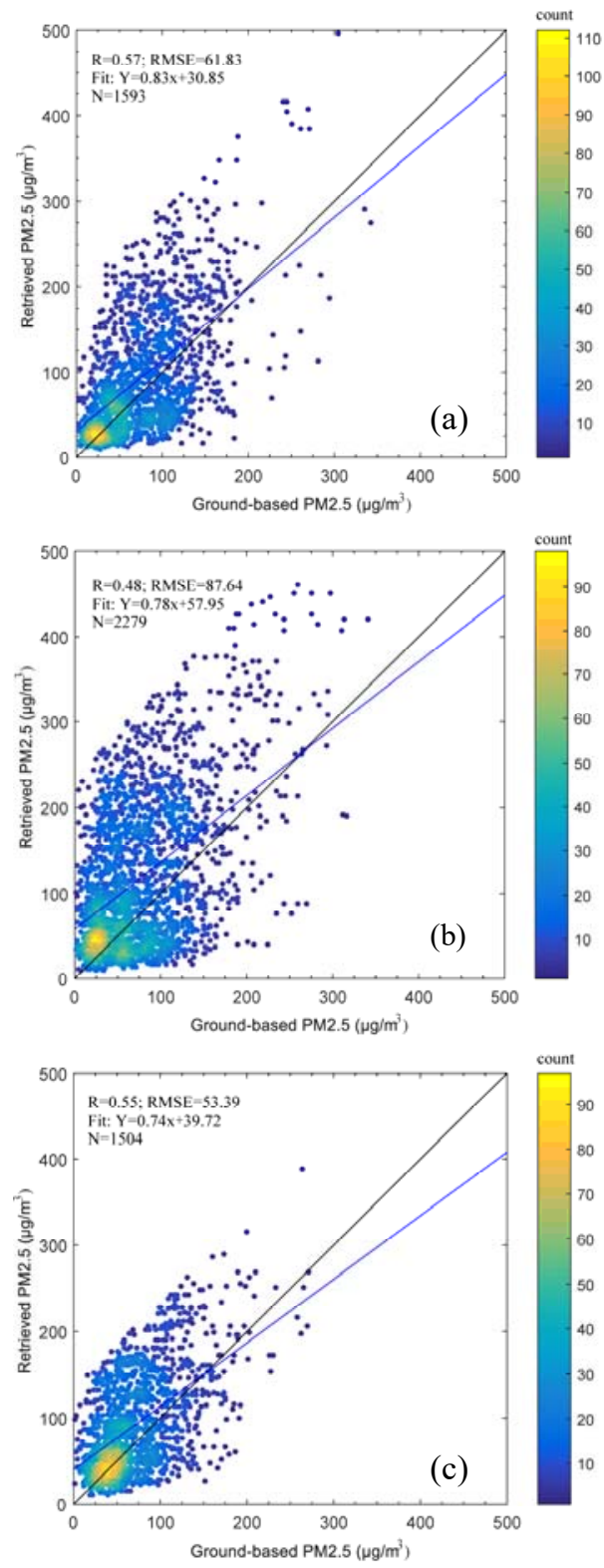
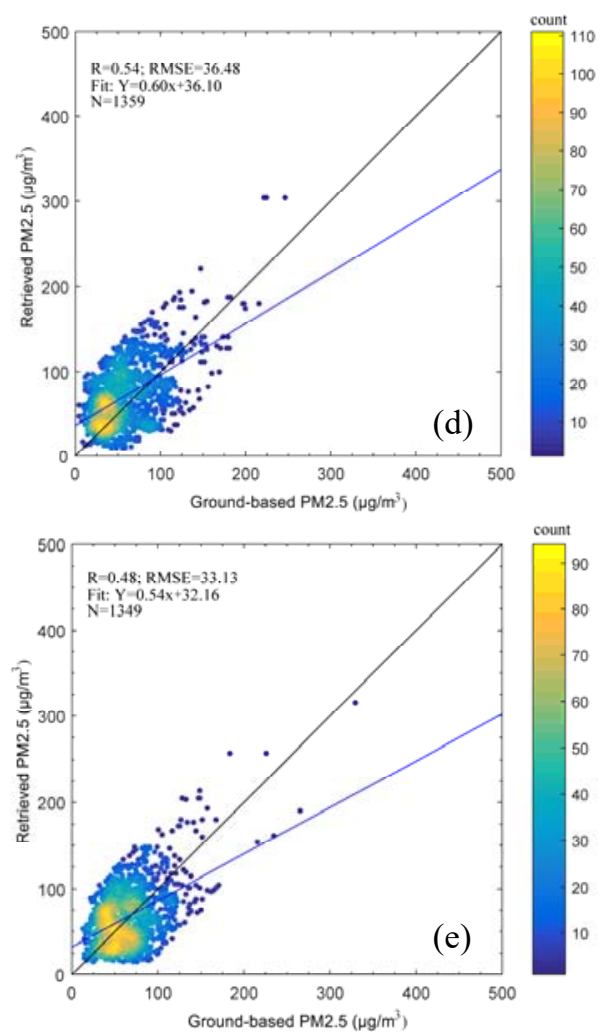

Figure 1. Density scatter plots of retrieved versus ground-based $\mathrm{PM}_{2.5}$ in (a) Beijing, (b) Shijiazhuang, (c) Tangshan, (d) Nanjing, (e) Changsha. The statistics from a linear least square fit the data points are shown in the upper left corners, with their corresponding equations, correlation coefficient $(R)$, the root mean square error (RMSE) and total number of observations $(N)$. The colours of dots represent density distribution of matches. The blue solid line is the regression line from two datasets and the black solid line represents identity line.

\subsection{Analysis of Spatio-temporal Variation Characteristics of $\mathbf{P M}_{2.5}$ in Central and Eastern China}

The annual variation and distribution of $\mathrm{PM}_{2.5}$ concentration in the Central and Eastern China from 2007 to 2016 was analysed based on MOD04/MYD04 data, BLH and RH re-analysis data using this physically based $\mathrm{PM}_{2.5}$ retrieval model. Annual averaged $\mathrm{PM}_{2.5}$ Concentration in Central and Eastern China from 2007 to 2016 are shown in Figure 2, from which it can be seen that in recent years, the annual mean value of this region showed a trend of gradually increasing and then decreasing, with the highest value in 2011 .

During the period of 2007 2009, the annual averaged $\mathrm{PM}_{2.5}$ concentration varies, and the area of high and low values is clearly divided. It was found that high concentrations of $\mathrm{PM}_{2.5}$ are mainly distributed in the densely populated and industrialized areas. High values are found in the northwest plain in Shandong province, Huai River Plain, Poyang Lake Plain, and the Yangtze River Delta (YRD) region (especially in areas along the Yangtze River, as shown in 2008). Very high values are found in Hebei Province. The low value is mainly distributed in the south-east China, and the lowest value appeared in Fujian province. From 2012 to 2016, the area with high $\mathrm{PM}_{2.5}$ concentration gradually decreases. In 2016, the high value $\left(\mathrm{PM}_{2.5}>100 \mu \mathrm{g} / \mathrm{m}^{3}\right)$ area reduced to Beijing, Tianjin in the 
north and parts of Hebei, Shandong, Henan provinces. The year-by-year decline in $\mathrm{PM}_{2.5}$ concentration is closely related to a series of air pollution prevention and control policies formulated by Chinese government. In December 2012, the "Twelfth Five-Year Plan" for the prevention and control of atmospheric pollution in key regions was formally issued by the Ministry of Environmental Protection, the National Development and Reform Commission, and the Ministry of Finance. This is the first comprehensive air pollution prevention and control plan in China. In 2013, "Air Pollution Prevention and Control Action Plan" was formally released and planned for the next five years (2013 2017). A new era of air pollution prevention and control in China was initiated.

The MODIS Ocean algorithm overestimates the AERONET coastal AOD by 0.021 for AOD $<0.25$ and underestimates it by 0.029 for AOD $>0.25$. This dichotomy is shown to be related to the ocean surface wind speed and cloud contamination effects on the satellite aerosol retrieval (Anderson et al., 2012). Hence, the concentration of $\mathrm{PM}_{2.5}$ on the coastal edge is relatively large, which suggest a need for future improvement over coastal regions.
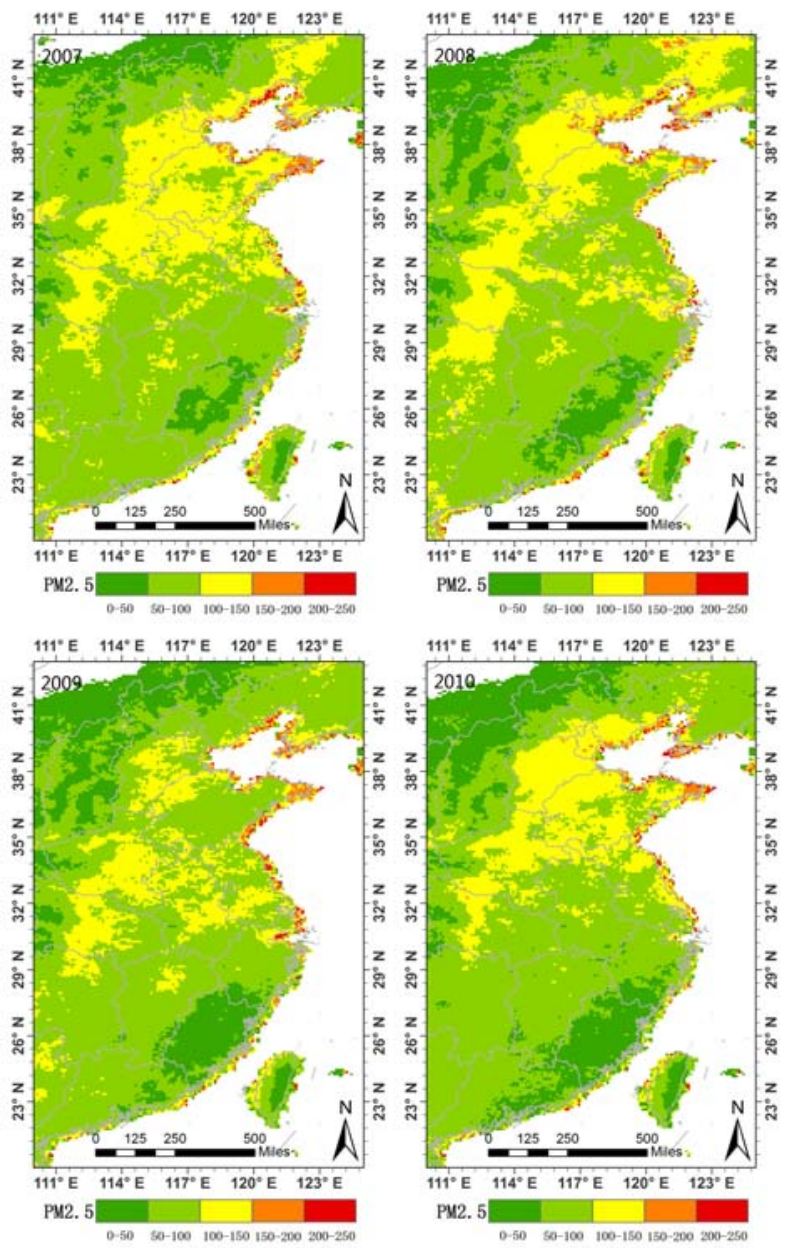
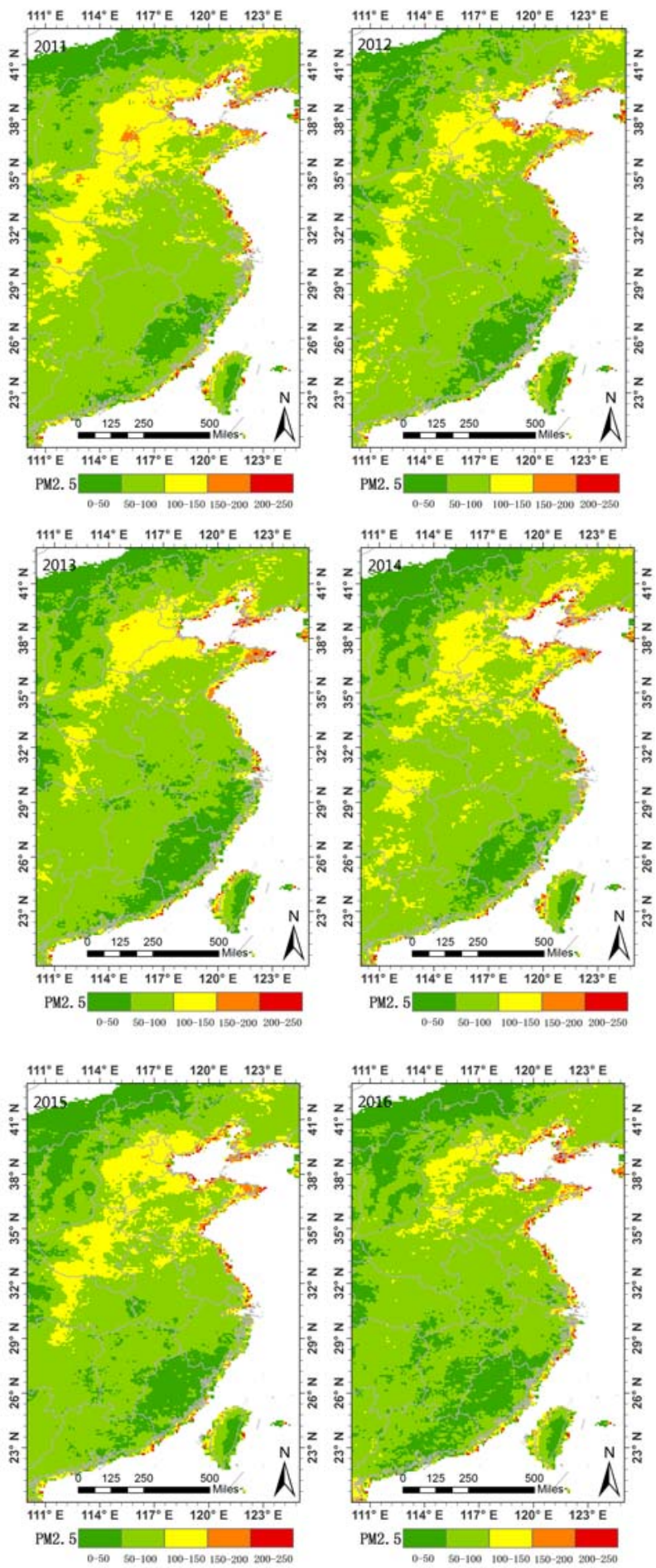

Figure 2. Annual averaged $\mathrm{PM}_{2.5}$ Concentration in Central and Eastern China from 2007 to 2016

\section{CONCLUSION}

Central and Eastern China is the region with the rapid economic development and dense population in China. Air pollution has been very serious which is closely related to the explosive growth of aerosol emissions in this region. As the prominent pollutant in most urban cities, $\mathrm{PM}_{2.5}$ is of great significance to local environmental governance. This paper develops a physically based AOD-PM 2.5 model and uses this model to get 
the annual variation and distribution of $\mathrm{PM}_{2.5}$ concentration in the Central and Eastern China from 2007 to 2016 based on MODIS AOD products, BLH and RH re-analysis data. From 2012 to 2016, the area with high $\mathrm{PM}_{2.5}$ concentration gradually decreases. $\mathrm{PM}_{2.5}$ retrieved results were compared with the ground-based $\mathrm{PM}_{2.5}$ data, with $R$ is greater than 0.54 in Beijing, Tangshan, and Nanjing city and RMSE is better than 36.48 $\mu \mathrm{g} / \mathrm{m}^{3}$ in Nanjing and Changsha city. This physically based $\mathrm{PM}_{2.5}$ retrieval model has the ability to retrieve $\mathrm{PM}_{2.5}$ without ground-based observation.

In order to further explore the potential of this physically based method for $\mathrm{PM}_{2.5}$ retrieval from satellite measurements, more work should be done in the future. Since the BLH and RH reanalysis data used in this paper is a spatial resolution of $0.125^{\circ} \times 0.125^{\circ}$, and the satellite AOD data is $10 \mathrm{~km} \times 10 \mathrm{~km}$. Resampling of the data may cause some errors during the retrieval of $\mathrm{PM}_{2.5}$. The accuracy of FMF (coarse and fine particle ratio) in MODIS data is not high, which causes certain errors. In future, other satellite data may be used or merged. When using satellite data to retrieve $\mathrm{PM}_{2.5}$, aerosol parameters such as effective particle radius $\left(R_{e f f}\right)$ and $<$ Qext $>$ in the physically based $\mathrm{PM}_{2.5}$ model is based on a fixed value of the aerosol type in this paper, which could be calculated with actual observations in the future.

\section{ACKNOWLEDGEMENTS}

This work was supported in part by the Ministry of Science and Technology (MOST) of China under Grand 2016YFC0200500, and by the National Natural Science Foundation of China under Grant nos. 41471306 and 41590855 and the Project of Humanities and Social Sciences of the Ministry of Education in China (NO.16YJCZH021). The data for analysis is come from AERONET, ECMWF and CNEMC. We thank the investigators and their staff for establishing and maintaining these important data used in this investigation. The authors would like to thank the reviewers for their constructive and helpful suggestions.

\section{REFERENCES}

Anderson, J.C., Wang, J., Zeng, J., 2012. Accuracy assessment of Aqua-MODIS aerosol optical depth over coastal regions: importance of quality flag and sea surface wind speed. Atmos. Meas. Tech. Discuss., 5, pp. 5205-5243.

Chen, G.L., Guang, J., Xue, Y., et al., 2018. A physically-based $\mathrm{PM}_{2.5}$ estimation method using AERONET data in Beijing area. IEEE Journal of Selected Topics in Applied Earth Observations and Remote Sensing, DOI: 10.1109/JSTARS.2018.2817243.

Dee, D.P., Uppala, S.M., Simmons, A.J., et al., 2011. The ERAInterim reanalysis: configuration and performance of the data assimilation system. Q. J. Roy. Meteor. Soc., 137(656), pp. 553597.

Guo, J.P., Miao, Y.C., Zhang, Y., et al., 2016. The climatology of planetary boundary layer height in China derived from radiosonde and reanalysis data. Atmos. Chem. Phys., 16(20), pp. 13309-13319.

Guo, Y., Nan, F., Sundar, A.C., et al., 2014. Satellite remote sensing of fine particulate matter (PM2.5) air quality over Beijing using MODIS. International Journal of Remote Sensing, 35(17), pp.6522-6544.
Hansen, J., and Travis, L., 1974. Light scattering in planetary atmospheres. Space Sci. Rev., 16(4), pp. 527-610.

Im, J.S., Saxena, V.K., and Wenny, B.N., 2001. An assessment of hygroscopic growth factors for aerosols in the surface boundary layer for computing direct radiative forcing. $J$. Geophys. Res., 106(D17), pp. 20213-20224.

Koelemeijer, R.B.A., Homan, C.D., and Matthijsen, J., 2006. Comparison of spatial and temporal variations of aerosol optical thickness and particulate matter over Europe. Atmos. Environ., 40(27), pp. 5304-5315.

Künzli, N., and Tager, I.B., 2006. Air pollution: from lung to heart. Swiss Med. Wkly., 35, pp. 47-48.

Levy, R.C., Mattoo, S., Munchak, L.A., et al., 2013. The Collection 6 MODIS aerosol products over land and ocean. Atmos. Meas. Tech., 6, pp. 2989-3034.

Levy, R.C., Remer, L.A., Tanré, D., et al., 2009. Algorithm for remote sensing of tropospheric aerosol over dark targets from MODIS: Collections 005 and 051(Revision 2). pp. 96.

Li, C.C., Mao, J.T., Liu, Q. H., et al., 2005. Application of MODIS satellite products to the air pollution research in Beijing. Sci. China Earth Sci., 48(s2), pp. 209-219.

Liou, K.N., 2004. An introduction to atmospheric radiation (2nd Ed.). Chinese translation. Beijing: China Meteorological Press, pp. 95-96.

Liu, Y., 2013. New directions: satellite driven PM2.5 exposure models to support targeted particle pollution health effects research. Atmos. Environ., 68(2), pp. 52-53.

Liu, Y., Paciorek, C.J., and Koutrakis, P., 2009. Estimating regional spatial and temporal variability of PM2.5 concentrations using satellite data, meteorology, and land use information. Environ. Health Persp., 117(6): pp. 886-892.

Liu, Y., Sarnat, J.A., Kilaru, V., et al., 2005. Estimating ground-level PM2.5 in the eastern United States using satellite remote sensing. Environ. Sci. Technol., 39(9), pp. 3269-3278.

Steiner, A.L., Mermelstein, D., Cheng, S.J., et al., 2013. Observed impact of atmospheric aerosols on the surface energy budget. Earth Interact., 17(14), pp. 1009-1009.

Tao, J.H., Wang, Z.F., Xu, Q., et al., 2015. Particulate matter mass extinction hygroscopic growth model in Beijing. $J$. Remote Sens., 19(1), pp. 12-24.

Tao, M., Chen, L., Wang, Z., et al., 2015. Comparison and evaluation of the MODIS Collection 6 aerosol data in China. $J$. Geophys. Res. Atmos., 120, pp. 6992-7005.

van Donkelaar, A., Martin, R.V., Brauer, M., and Boys, B.L., 2014. Use of satellite observations for long-term exposure assessment of global concentrations of fine particulate matter. Environ. Health Persp., 123(2), pp.135-143.

von Engeln, A., and Teixeira, J., 2013. A planetary boundary layer height climatology derived from ECMWF reanalysis data. J. Climate, 26(17), pp. 6575-6590. 
Wang, M., Zou, B., Guo, Y., et al., 2013. BP artificial neural network-based analysis of spatial variability of urban PM2.5 concentration. Environ. Pollut. Control, 35(9), pp. 63-66.

Xie, Y.Y., Wang, Y.X., Zhang, K., et al., 2015. Daily estimation of ground-level PM2.5 concentrations over Beijing using $3 \mathrm{~km}$ resolution MODIS AOD. Environ. Sci. Technol., 49(20), pp. 12280-12288.

Yan, X., Shi, W., Li, Z., et al., 2017. Satellite-based PM2.5 estimation using fine-mode aerosol optical thickness over China. Atmos. Environ., 170, pp. 290-302.

Zhang, Y., and Li, Z., 2015. Remote sensing of atmospheric fine particulate matter (PM2.5) mass concentration near the ground from satellite observation. Remote Sens. Environ., 160, pp. 252-262.

Zhang, Y.Y., Zhu, J.M., Gao, Z.Y., et al., 2016. Research on the factors affecting the content of $\mathrm{PM}_{2.5}$ based on multiple linear regression model. J. Xichang Coll. (Nat. Sci. Ed.), 30(1), pp. $17-20$. 